УдК 331.101

\title{
ЭВОЛЮЦИЯ ТРАКТОВКИ ПОНЯТИЯ «УПРАВЛЕНИЕ ТРУДОМ В ПРОМЫШЛЕННОСТИ»
}

\author{
Т.В. СЕРГИЕВИЧ \\ магистр экономических наук, старший инспектор Минской региональной таможни, \\ г. Минск
}

Аннотация

Статья посвящена генезису управления трудом в промышленности. Был обоснован момент зарождения управления трудом как науки, выделены основные существующие научные подходы к управлению трудом в промышленности, проанализированы предпосылки их возникновения и становления, влияние на дальнейшее развитие трудовых отношений.

Abstract

The article is dedicated to genesis of labor management in industry. There were marked out the main scientific approaches to the labor management in industry, analyzed the premises of its origination and formation, the influence on further development of labor relations.

\section{ВВЕДЕНИЕ}

История управления трудом как науки насчитывает полтора века. За этот период сменилось несколько подходов и школ, изучающих процесс организации трудящихся в целях повышения результативности и эффективности деятельности предприятия. Концепция управления прошла развитие от научной организации труда до управления человеческими ресурсами, от жесткого контроля и детерминации рабочего поведения до признания эффективным снижение контроля, наделение работников свободой и ответственностью, поощрение инициативы и творческого труда. Такая трансформация содержания понятия «управление трудом» связана, среди прочего, с переходом от индустриального к постиндустриальному типу общества, одной из важнейших особенностей которого является изменение в структуре занятости, повышение роли знания и компетенций, спрос на работников высокой квалификации.

Научные школы управления трудом активно развивались в странах Северной Америки, Западной Европы, Японии. Развитие данного научного управления тесно связано с другими областями науки, такими как социология, психология, математика, синергетика, эргономика. Основоположниками науки управления трудом, стали Ф. Тейлор, А. Файоль, Э. Мэйо, Ф. Герцберг, А. Маслоу, М. Армстронг, П. Друкер. Все разработанные концепции в той или иной мере были подвержены критике, однако большинство их них не теряет своей актуальности и сейчас, и изучая их, можно извлечь полезные уроки для современных теоретических и практических подходов к управлению трудом.

В литературе существуют различные варианты периодизации науки управления трудом. На основе проработки литературы автором был выбран подход, отвечающий объективным критериям периодизации. На современном этапе рано говорить о полноценном сформированном подходе к управлении трудом в промышленности, который решил бы существующие проблемы, такие как дисбаланс в структуре спроса и предложения на рабочую силу, неудовлетворенность трудом, высокие показатели безработицы, «догоняющее», а не «опережающее» образование. В этой связи проработка проблемы управления трудом в промышленности представляется особенно актуальной.

\section{РЕЗУЛЬТАТЫ И ИХ ОБСУЖДЕНИЕ}

Возникновение деятельности по управлению трудом можно отнести к моменту зарождения человеческой цивилизации, когда сформировалась первая форма общественного труда в виде коллективной работы. Впоследствии, благодаря совершенствованию орудий труда повышалась производительность труда, происходили процессы разделения труда, первоначально - на земледелие, скотоводство и ремесленничество. Растущее население требовало большего количества ресурсов, поэтому первые государственные образования возникли в бассейнах больших рек Передней Азии и Северной Африки - местах, где климатические и географические условия способствовали занятию земледелием. Реализация строительных проектов, таких как ирригационные системы, требовало большого количества рабочей силы, что привело к созданию такой формы трудовых отношений, как рабство, предполагавшее наличие большого количество человеческих ресурсов, требующих организации и управления. Классическим примером организации труда в древнем мире стало строительство египетских пирамид 2,5 тысячи лет до н.э., что требовало решения проблем занятости, организации распределения работ, рабочего времени, довольствия и оплаты труда, санкций. В проведенных исследованиях было выяснено, что египетские пирамиды были построены вовсе не рабами, а вольнонаемными рабочими из различных слоев населения Египта, которые были мобилизованы для строительства пирамид [8]. Это свидетельствует о высочайшем на тот период времени уровне организации работ. Вклад в развитие управленческой практики был сделан в Вавилоне благодаря созданию Кодекса Хаммурапи, в котором в 1750-х годах до н. э назад были юридически оформлены многие вопросы оплаты труда, в том числе минимальной заработной платы, контроля и ответственности, отношений собственности на результаты труда наемных работников. О становлении практического управления трудом можно говорить и в период развития феодального общества, основу которого составляло право 
крупных землевладельцев распоряжаться средствами производства (прежде всего землей) и трудом самостоятельно хозяйствовавших производителей, которые находились в поземельной, а часто и в личной зависимости от землевладельцев-феодалов. В период становления экономической науки исследования затрагивали и вопросы труда. В частности, А. Смит говорил не только о разделении труда, о мотивации, о повышении производительности труда, но и доказал влияние труда на благосостояние нации.

Однако, во-первых, в данной работе речь идет об управлении трудом в промышленности, поэтому целесообразно рассматривать эволюцию управленческой парадигмы начиная с XIX-го века, с эпохи промышленного переворота, а во-вторых следует различать практическое управление персоналом и управление персоналом как область знаний и научную дисциплину. Период, когда управление трудом носило традиционный, исключительно практический характер, можно обозначить как «донаучный этап». Формирование первого научного подхода к управлению трудом относят к концу XIX - началу XX века, когда социально-экономическое развитие стран-лидеров достигло такого этапа, когда накопленные эмпирическим путем знания должны были вылиться в теоретическое обоснование проблем управления трудом.

Систематизация опыта управления началась еще на рубеже XVIII-XIX веков, когда в мировом хозяйстве наблюдался стремительный рост производительных сил на базе крупной машинной индустрии и утверждался капитализм. Развитие торговли, накопление капитала, протекционистские меры в английской экономике, научный прогресс, распространение применения наемного труда, развитие институтов частной собственности привели к промышленной революции, которая связана была не только с началом массового применения машин, но и с изменением всей структуры общества. Промышленная революция сопровождалась и тесно с ней связанной производственной революцией в сельском хозяйстве, ведущей к существенному росту производительности земли и труда в сельскохозяйственном секторе, что привело к перемещению значительных масс населения из деревень в города в поисках рабочих мест. В XIX веке миграция стала массовым явлением как в Европе, так и в Северной Америке. Этому способствовало также изобретение и развитие железной дороги, что повысило мобильность населения. Появление дешевых промышленных товаров привело к разорению ремесленников, которым приходилось пополнять ряды наемных рабочих. Большая часть населения представляла из себя неквалифицированную рабочую силу, которая не могла справиться с всеобъемлющей широкой задачей производства продукции, но была успешно применима в мельчайших операциях на производстве, сумма которых позволяла получать сложную продукцию [5, с. 16]. Одним из достижений промышленной революции стало распространение относительно недорогого освещения газовых фонарей в начале XIX-го века, что привело к удлинению рабочего дня на фабриках и заводах, ранее зависевших от освещения сравнительно дорогостоящими свечами и масляными лампами. Эти факторы привели к росту производительности и росту масштабов производства. Наука развивалась не только в технической сфере, но и в здравоохранении. Благодаря революционным открытиям в науке и медицине, таким как вакцинация, рентгеновское излучение, анестезия, усовершенствование микроскопа, произошел рост средней продолжительности жизни и количества населения, что вкупе с распространением детского и женского труда привело к увеличению количества трудовых ресурсов, которые требовали организации в процессе труда. Вместе с тем происходила централизация прав собственности, приведшая к появлению крупных промышленных предприятий. Все эти факторы сформировали необходимость поиска путей оптимизации организации труда.

Англия как одна из первых стран, в которых произошел промышленный переворот, стала лидером и в разработке теории управления трудом. С расширением практических потребностей руководителей капиталистическими предприятиями возникали предпосылки для формирования науки управления трудом. Английский ученый Ч. Бэбидж, профессор математики, инженер и предприниматель, в 1832 г. опубликовал книгу «Экономика машин и производства», в которой впервые были системно рассмотрены проблемы организации труда, роль машин в разделении труда, принципы контроля над издержками производства, пути понижения затрат и др. Фактически это стало первым значительным учебным пособием по управлению промышленными предприятиями [7, с. 7]. Это был анализ, основанный на экономических принципах, в частности, на оценке разделения труда А. Смита, производственной технологии и организации промышленности. Непосредственное знание Ч. Бэббиджем множества промышленных и деловых процессов в сочетании с общим анализом производственных систем, сделало работу выдающимся явлением. Выделяя умственный и физический труд, Ч. Бэббидж говорил о целесообразности разделения труда на множество процессов, а также анализировал роль скорости производства и интенсивности труда в увеличении выпуска. Введение машинного оборудования было только одним из факторов роста производительности. Производительность труда могла быть быстро повышена за счет усиления порядка, точности и дисциплины труда. Ч. Бэббидж доказал эффективность сдельной оплаты труда коллективного принятия решений по поводу найма, увольнения и организации работ, положив начало научному подходу к управлению трудом в промышленности.

Немало плодотворных мыслей об управлении было высказано великими социалистами-утопистами XIX века, которые искали наиболее рациональный способ управления для конструируемых ими идеальных социальноэкономических систем. В особенности это относится к англичанину Р. Оуэну, который доказывал, забота о наемных рабочих может быть выгодна и для самого работодателя. Р. Оуэн дал первый толчок фабричному законодательству, указал на необходимость вмешательства государства и поставил задачу борьбы с безработицей; его же можно считать отцом той теории кризисов в промышленности, которая объясняет их несоответствием производства с потребительными бюджетами масс или, с незначительностью потребительной доли богатства, которая достаётся массам при системе соперничества. Основой поддержания хороших отношений между работодателями и работниками на фабрике, по мысли Р. Оуэна, является уважительное отношение к рабочим и исключение конфликтов. Он ясно видел недостатки чрезмерного разделения труда, которое, по его словам, создает «жалкую ограниченность человеческого интеллекта», при которой возникают «ущербные и ничтожные в своих частных интересах существа». В результате целого ряд 
социальных экспериментов, проведенных на фабрике, он сумел повысить экономическую эффективность своего предприятия [7, с. 9].

Символическим отправным пунктом развития теории индустриального управления при капитализме считается 1886 г., когда Генри Р. Таун - президент мануфактурной компании Йель энд Тауни - на ежегодном собрании Американского общества инженеров-механиков представил доклад на тему «Инженер как экономист». В нем он впервые отчетливо поставил вопрос о роли управления как относительно самостоятельной сферы научного знания и профессиональной специализации, по своей практической значимости не уступающей инженерному труду. Г. Таун доказывал, что управление должно быть конституировано в особую науку со своим предметом, объектом, литературой, т.к. лишь в этом случае предприниматели и менеджеры смогут извлекать взаимную пользу из совместного опыта. Он считал, что инженеры должны развивать в себе качества управляющих производством: только таким путем профессиональные навыки и специализированные знания соединяются с организаторской работой. В функции инженера, по словам Г. Тауна, входят обязанности по организации труда и надзору за проводимыми работами, поскольку сила организованных условий берет верх над искусностью индивидуального работника. Поэтому инженеры в целях обеспечения наилучших производственных результатов возглавляемых ими подразделений должны быть людьми не только с хорошими административными способностями, обнаруживающими практическое знакомство с профессией механика, но должны обладать также особым знанием и навыками проведения экономических и организаторских работ, необходимых для функционирования всей производственной системы. Интересы фирм требовали значительно более широкого вовлечения специалистов в процессы управления. Задача менеджеров состояла в том, чтобы включить специалиста в структуру власти фирмы и дать ему больше автономии, чем рабочему, для развития в нем стремления идентифицировать свои собственные интересы с интересами фирмы. Заслуга Г. Тауна и его последователей заключается в том, что они впервые целенаправленно обратились к внутриорганизационным проблемам компаний и фирм, к тому времени переросших из простых мануфактурных предприятий в сложные организационные системы с развитой специализацией, состоящих из множества разнородных элементов, интегрированных в единое целое. Это означало формирование научного подхода к управлению трудом.

Отцом менеджмента принято считать Ф. Тейлора, который стал основоположником школы научного управления. Главным вопросом, который он ставил, был «как повысить производительность труда?» Рассматривая человеческую энергию как ценный ресурс, Ф. Тейлор доказал, что вследствие нерационального использования этого ресурса экономика предприятий и страны в целом терпит огромные убытки и избежать их можно путем систематической организации труда. Заслуга Ф. Тейлора заключается и в том, что он назвал оптимальную организацию труда наукой, которая опирается на свои законы и правила. По словам Ф. Тейлора, «главнейшей задачей управления предприятием должно быть обеспечение максимальной прибыли для предпринимателя, в соединении с максимальным благосостоянием для каждого занятого в предприятии работника» [6]. При этом под максимальной прибылью он понимал не только дивиденды для собственника, но и «развитие каждой отдельной отрасли дела до наивысшей ступени совершенства, обеспечивающей постоянный характер реализации этой прибыли», а под максимальным благосостоянием каждого работника - не только вознаграждение, но и «развитие каждого работника до максимально доступной ему степени производительности, которая позволила бы ему давать труд самого высокого качества, в пределах его естественных способностей; и далее, оно означает предоставление ему, по возможности, работы именно этого качества» [6]. Речь идет о том явлении, которое сегодня мы называем экономической и социальной эффективностью управления. И поиск оптимального соотношения интересов работника и работодателя - проблема, пути решения которой искал Ф. Тейлор, не теряет своей гносеологической ценности и сейчас. Основной проблемой в промышленности и в экономике в целом, Ф. Тейлор считал намеренную медлительность людей в работе. Уничтожение этой проблемы, по словам Ф. Тейлора, «должно настолько понизить издержки производства промышленности, что как наш внутренний, так и наш внешний рынок значительно расширятся, и мы сможем конкурировать более чем на равных условиях, с нашими соперниками». Все это должно привести к снижению безработицы, нищеты, обеспечить высокую заработную плату при сокращении рабочего дня, к улучшению условий труда и жизни рабочих. Таким образом, важнейшей задачей для администрации предприятия и самих рабочих, по Ф. Тейлору, является «обучение и развитие каждого отдельного работника в предприятии для того, чтобы он мог давать труд наивысшего качества и притом тот, к которому он наиболее способен по своим естественным склонностям». Такой подход позволяет сделать вывод о том, что человек рассматривался как издержки для предприятия, а также то, что работник сознательно старается замедлить темп своей работы не только в силу природных стремлений к праздному времяпрепровождению, но и с целью утаить от работодателя предельный возможный объем выполненной работы в день. Для внедрения системы научного управления администрация должна выполнять ряд новых функций, таких как выработка научного фундамента для каждого действия работников на предприятии, тщательный отбор, обучение и развитие рабочих, сотрудничество с рабочими, а также распределение труда и ответственности между администрацией предприятия и рабочими. Практические рекомендации к управлению трудом заключались в необходимости отбора наиболее подходящих рабочих, точного исследования всех операций, движений и используемых инструментов этих рабочих, фиксация и выбор кратчайшего периода времени для выполнения функций, устранении всех прочих движений. Ф. Тейлор говорит и о необходимости формирования «дружественного сотрудничества» между управлением и рабочими, которое должно заключаться в возможности работников пользоваться советами и помощью руководителей. Ф. Тейлор так характеризовал свою систему: «Наука вместо традиционных навыков, гармония вместо противоречий, сотрудничество вместо индивидуальной работы, максимальная производительность вместо ограничения производительности, развитие каждого отдельного рабочего до максимальной доступной ему производительности и максимального благосостояния» [7, с. 9]. За первые тридцать лет XX века система Ф. Тейлора распространилась достаточно широко не только в США, но и в Германии, Ан- 
глии, Франции, Швеции. На тех предприятиях, где система была внедрена, средняя производительность труда за три года возросла в два раза. Ее применяли «под флагом рационализации, научной организации труда, что позволяло снизить издержки капиталистического производства, хотя сам Ф. Тейлор чувствовал, что применение его «новшества» вызвало обострение классовых антагонизмов» [5, с. 14].

Научную школу Ф. Тейлора развивали Г. Гант, Ф. и Л. Гилберт. Г. Гант изучал вопросы производительности персонала и в целях ее повышения предлагал создать систему четкого календарного планирования деятельности предприятий, что позволило более четко формулировать задачи и осуществлять контроль их исполнения. Одним из изобретений Г. Ганта является система заработной платы с элементами повременной и сдельной форм оплаты. Ф. и Л. Гилбрет развивали концепцию микроэлементного нормирования в производственном труде. В своих работах «Азбука научной организации труда» и «Изучение движений» Ф. Гилберт искал возможности для устранения всех лишних движений рабочего и установления более точных рабочих норм выработки. Ф. Гилбрет первым применил фотоаппарат для исследования движений работников. Исследования вопросов рационализации труда рабочих, проводимые Ф. Гилбертом, обеспечивали трехкратное повышение производительности труда. Л. Гилбрет первой начала заниматься научным подбором, расстановкой и подготовкой кадров, положив начало области управления, которая теперь называется «управление кадрами».

С ростом масштабов производства, освоением новых рынков сбыта, подъемом производства, связанным с первой мировой войной, с созданием поточного производства Г. Фордом и появлением таких промышленных гигантов, как «Форд» (1903 год), «Дженерал Моторс» (1908 год), «Standard Oil» (1870 год), Levi Strauss \& Co (1853 год), «Боинг» (1916 год), «Юнион карбайд» (1917 год), General Electric (1892 год), Procter \& Gamble (1837 год), Pfizer (1849 год), Johnson \& Johnson (1886 год), возрастала необходимость применения новых подходов в управлении, где наука управления персоналом была бы тесно интегрирована в управление организацией в целом, где на первый план выходило бы повышение эффективности работы всего предприятия. Это привело к развитию науки управления путем формирования классического подхода или административной школы управления, представителями которой стали А. Файоль, М. Вебер, Г. Эмерсон, Л. Урвик. Создатели классической школы имели непосредственный опыт работы в качестве руководителей высшего звена управления в большом бизнесе, поэтому их интересы были связаны с эффективностью работы всей организации. Классики пытались определить общие характеристики и закономерности организаций. Развитие административной школы происходило по двум направлениям: рационализация производства и исследование проблем управления. Целью этой школы было создание универсальных принципов управления, реализация которых обязательно приведет к успеху.

Г. Эмерсон вплотную занимался проблемой повышения производительности труда. Его основными работами стали «Производительность как основание для управления и оплаты труда», и «Двенадцать принципов производительности». Понятие производительности, или эффективности, есть то основное, что внес Г. Эмерсон в науку управления, он впервые поставил вопрос об эффективности производства в широком смысле. Эффективность, по Г. Эмерсону, означает максимально выгодное соотношение между совокупными затратами и экономическими результатами. Г. Эмерсон отводил значительное место в управлении для постановки четких целей, был приверженцем нормирования операций, которое заключалось в стандартизации способов их выполнения и регламентирования времени благодаря созданию письменных инструкций, а также выступал за справедливость в управлении персоналом, в том числе и в вопросах вознаграждения. Г. Эмерсон поставил и обосновал вопрос о необходимости и целесообразности применения комплексного, системного подхода к решению сложных многогранных практических задач организации управления производством и всякой деятельности вообще.

Представители классического подхода исследовали эффективность организации как целого: принципы рационального управления организацией, функции управления, структуру системы управления. В понятие «управление» А. Файоль включил 6 функций: производственную (техническую), коммерческую, финансовую, защитную (защита собственности и личности), бухгалтерскую, административную. В последующем в этот набор функций управления вносились различные изменения, но в основе остался подход А. Файоля. Ученый исследовал содержание и соотношение этих функций у руководителей разного уровня и определил совокупность качеств и знаний, через призму которых следует рассматривать содержание труда управленцев разного уровня. Эти качества, по мнению ученого, должны быть сведены в такие группы: физические качества, умственные качества, нравственные качества, общее развитие, специальные знания, опыт. Здесь четко прослеживается идеология построения жесткой централизованной иерархической организации, в которой персонал должен проявлять инициативу и разделять цели руководства [7, с. 16]. Предприниматель, организатор, ученый, А. Файоль был первым исследователем, классифицирующим изучение управления по его функциональным признакам, таким как планирование, организация, распоряжение, координация, и контроль. Главный вклад А. Файоля в теорию управления состоял в том, что он рассмотрел управление как универсальный процесс, состоящий из нескольких взаимосвязанных функций. А. Файоль пришел к заключению, что личность администратора весьма существенна для процветания организации. Если А. Файоль исследовал функциональный аспект менеджмента, то М. Вебер развивал институциональный аспект. Его основная работа «Теория общества и экономическая организация» посвящена анализу проблемы лидерства и бюрократической структуре власти в организации. М. Вебер выделил три основных типа организаций в зависимости от характера власти, которой обладает руководитель: харизматический, традиционный и идеальный (или бюрократический).

Несмотря на декламированную выгоду от применения научного подхода к управлению трудом не только для нанимателя, для всей нации, но и для каждого отдельного работника, новая система не всегда приводила к положительным результатам, таким как повышение прибыли для предприятия и повышение заработной платы для работников. «Дружественные отношения» между работником и работодателем не налаживались, как обещал Ф. Тейлор, а 
недовольство рабочих и число забастовок росло. Это было связано, в том числе, с неудачными поспешными попытками введения новой системы, неприятием людьми всего нового, используемыми насильственными методами заставить рабочих выполнять больший объем работы без значительного увеличения оплаты и благосостояния, потерей работы большим количеством людей, не готовых повысить выработку в несколько раз. Зачастую на практике внедрение научного подхода в управлении ограничивалось исключительно увеличением требований к труду работника. В начале $\mathrm{XX}$ века активизировалось профсоюзное движение с целью защиты прав работников в трудовых отношениях. Распространение научного и административных подходов в управлении трудом способствовало «более интенсивной эксплуатации работников, усилению текучести кадров, обострению противоречий между собственниками предприятий и наемными работниками, препятствовало распространению принципов партнерства, социальной справедливости, гармонии и сотрудничества в рамках предприятия» [4, с.223]. Это объясняется тем, что работник не был ценным ресурсом для организации, труд не был высококвалифицированным, и, следовательно, работник был легко заменимым, особенно в условиях превышения предложения рабочей силы над спросом. Человеческому фактору отводилась второстепенная функция. Ситуация на рынке труда менялась по мере совершенствования производства, с развитием научно-технического прогресса, повышением квалификации трудовых ресурсов, ростом потребности в квалифицированном персонале, ростом всеобщего благосостояния. Многие рекомендации классической школы утрачивали свою актуальность. Еще со времен А. Смита и предложенной им материальной мотивации к труду исследователи не акцентировали внимание на поисках иных стимулов и систем мотивации. В начале ХХ века концепция «экономического человека», в рамках которой главным стимулом человеческой деятельности была материальная заинтересованность, была подвергнута критике. Получает свое развитие концепция «социального человека», предполагающая, что кроме материальной выгоды работник стремится к удовлетворению моральных потребностей (приобретение социального статуса, признание и уважение коллег, саморазвитие, самовыражение и т.д.) [4, с.225]. С другой стороны, противодействие большинства рабочих системе Ф. Тейлора заставило предпринимателей искать новые методы управления человеческим фактором производства, что привело к становлению новой теории управления на рубеже $20-30$-х годов $\mathrm{XX}$ века - теории «человеческих отношений», которая обещала добиться повышения эффективности труда иными средствами.

Одним из первых ученых, кто заговорил о зависимости производительности труда от психологических факторов, стал Г. Мюнстерберг, положивший начало научному подходу к выбору профессий и обосновал зависимость производительности труда от психофизических возможностей человека $[7$, с.18]. Теория «человеческих отношений», также как и научный подход к управлению, была неразрывно связана с практикой и опиралась на проведенные измерения и эксперименты. Э. Мэйо с группой исследователей в целях усовершенствования научного подхода в процессе изучения влияния внешних факторов на производительность труда пришел к выводам, что влияние имеют, в первую очередь, социальные факторы, а не физические, при условии, что определенный уровень повышенной эффективности уже достигнут. В результате Э. Мэйо подверг критике научный и классический подходы к управлению трудом за то, что в них не уделялось должного внимания работнику как социальному субъекту. Э. Мэйо, как психолог и социолог, подчеркивал значимость социальной составляющей жизни человека, в особенности в условиях кризиса американского общества и падения роли традиционных социальных институтов. К социальным факторам были отнесены такие как отношения в коллективе, сплоченность группы, взаимоотношения с руководством, благоприятная атмосфера на рабочем месте, удовлетворенность трудом, осознание своей значимости и ответственности и другие. Если научный подход предполагал индивидуальное вознаграждение и экономическое поощрение, то школа человеческих отношений - коллективное или групповое вознаграждение и социально-психологическое поощрение. Таким образом, подчеркивалась роль отношения человека к группе, значимость интересного содержания труда, необходимость перехода от жесткого и авторитарного стиля управления к демократическому, а также формирование нематериальной системы мотивации. Для повышения производительности труда Э. Мэйо предложил обеспечить благоприятные технико-технологические условия труда, создать благоприятную атмосферу в коллективе и в отношениях с руководством, а также обучение работников и повышение квалификации. Школа человеческих отношений стала попыткой менеджмента рассматривать каждую организацию как социальную систему.

Однако ни Ф. Тейлор, ни Э. Мэйо не интересовались мнением самих работников, они говорили сами. Как оказалось впоследствии, рабочие многое знали о своей работе, о логике, о ритме, качестве и инструментах. Их мнение и идеи могли повысить производительность и эффективность труда. В 50-х гг. ХХ в. во многих странах мирового хозяйства начался пересмотр принципов экономической политики. В теории и практике управления персоналом на первый план вышли воззрения, делавшие акцент на активности, предприимчивости, индивидуализации присвоения и максимизации удовлетворения потребностей работников [4, с. 225]. В условиях сочетания научной организации труда и рабочего места и повышенным вниманием к работнику возникла необходимость разработать систему мотивации, отличной от традиционной экономической. Уже в то время стала очевидной прямая зависимость утверждения в мотивационных установках работников нематериальных факторов от повышения уровня жизни и благосостояния в целом. Основным направлением исследований представителей возникшей поведенческой школы управления трудом стала попытка дать научное обоснование роли мотивов и потребностей человека в его трудовой деятельности. Они рассматривали мотивы как главный показатель отношения людей к труду. Значительный вклад в разработку теорий мотивации внесли А. Маслоу, Ф. Герцберг, Д. Макгрегор, Р. Лайкерт, К. Арджирис, К. Альдофлер. Основным фактором эффективности труда было отношение работника к своему труду. Сторонники поведенческого подхода критиковали школу человеческих отношений за невнимание к содержанию труда, утверждая, что лучшим мотиватором к эффективной деятельности является интересная работа, где имеет место самостоятельность, возможность участия в решениях, признание, поощрение инициативы. 
Самой известной теорией мотивации является теория, основанная на иерархии потребностей, созданная А. Маслоу. В модели А. Маслоу существует пять уровней потребностей - физиологические потребности, потребность в безопасности, социальные потребности, потребность в уважении, потребность в развитии. Как отмечает И.С. Килин, «процесс последовательного перехода с низшей ступени потребности на высшую соответствовал парадигме менеджмента начала второй половины XX века» [3, с. 61]. Хотя в пирамиде потребностей А. Маслоу отсутствует потребность в труде как таковая, существует ряд потребностей, которые могут быть удовлетворены посредством труда, так, например, потребности в самоуважении и самоактуализации. Однако, по мнению, А. Маслоу, далеко не все люди достигают вершины пирамиды. Эта теория часто подвергалась критике в виду того, что в ней не учитываются индивидуальные особенности людей, а также из-за строго иерархичного, не соблюдаемого на практике порядка потребностей. Работы К. Альдофлера стали развитием разработок А. Маслоу. Модель К. Альдофлера объединяет три уровня существование (биологические потребности), принадлежность (социальные потребности) и рост (потребности в развитии). Важное отличие концепции К. Альдорфера от концепции А. Маслоу состоит в том, что переход от одного уровня потребностей на другой может осуществляться в любом направлении [3, с. 61]. Ф. Герцеберг плотнее работал с трудовой мотивацией и предложил двухфакторную теорию, где разделил трудовые мотивы на две группы - «гигиенические факторы» и «мотиваторы». Эта теория также была подвергнута критике, т.к. деление мотивов на устраняющие неудовлетворенность и повышающие мотивацию достаточно условно и индивидуально. Теория высших потребностей Д. Мак-Клелланд выделяет потребность во власти, успеха и причастности. Д. Мак-Клелланд игнорировал потребности низших уровней. Важным фактором в мотивации работников является высокий уровень социального общения. По его мнению, мотивация лежит в основе экономического процветания. В. Врум дополнил теорию мотивации такими переменными, как ожидание удовлетворения потребности по результатам определенной деятельности и ценность вознаграждения (валентность). В. Скиннер рассматривал поведение человека как результат прошлого опыта, предшествующих воздействий окружающей среды. В отношении трудового поведения человека теория В. Скиннера объясняет поведение человека, который стремится повторить действия, принесшие ему в прошлом успех или вознаграждение, и избежать тех действий, которые принесли негативные результаты. Теория «Х» и «У» Д. Макгрегора детерминирует поведение работника различными стилями управления - административным и демократическим.

Большинство теорий мотивации подвергаются критике по той причине, что они слабо учитывают индивидуальные различия типов работников. Однако учитывая тот факт, что объектом исследования мотивации является человек со свойственной ему индивидуальностью, выработать универсальную мотивационную теорию, которая бы подходила для каждого типа личности и уровня квалификации, уравнивая работников физического и интеллектуального труда, вряд ли представляется возможным. По этой причине и не существует объединяющей теории мотивации, все гипотезы существуют параллельно, дополняя друг друга и рассматривая трудовое поведение человека из разных углов. Вместе с тем при практическом применении любой из теорий мотивации необходимо ориентироваться не только на трудовые отношения и корпоративную культуру организации, но и на экономическую ситуацию в стране.

В последней четверти ХХ века сформировалась концепция «управления человеческими ресурсами», построение моделей которой основывается на системном подходе. Основными представителями этого направления стали М. Армстонг, Е. Лоулер, Дж. Пфеффер, М. Хьюзелид, С. Вуд, Дж. Дуглас, С. Клейн, Д. Хант, Э. Шейн, М. Биер, П. Боскал, Д. Гест, Д. Стори. Изменения в сфере трудовых отношений стали одним из элементов перехода общества к постиндустриальному типу, которое характеризуется, среди прочего, изменениями в структуре занятости и трансформацией содержания труда. Работник нового типа становится высококвалифицированным. Особенностью формирующейся системы трудовых отношений является дефицит кадровых ресурсов, что связано с высокими требованиями, предъявляемыми организацией к работнику и, наоборот, с узкой специализацией знаний. В условиях нехватки кадров нужной квалификации не работники конкурируют между собой, а работодатели. Это приводит к изменению отношения к работнику, форма связей «начальник-подчиненный» трансформируются в форму «коллеги». Менеджер в новом обществе должен научиться управлять в условиях, когда нет права приказывать и контролировать каждое действие работника [2]. Экономический рост на современном этапе базируется на техническом прогрессе, который невозможен без развития науки и образования, а также на социальных инновациях. Технология и организация производства усложняется, что обуславливает необходимость использовать квалифицированную рабочую силу. П. Друкер замечает важное отличие новой парадигмы в управлении. Традиционную рабочую силу делала производительной система, т.к. она позволяла отдельным работникам выполнять функции без особых знаний и навыков. В организации, основанной на знаниях, эффективность работы отдельного сотрудника обеспечивает успех всей системы. «Традиционный работник обслуживает систему; однако для интеллектуальных работников справедливо обратное: система должна обслуживать работника» [2, с. 68].

М. Армстронг определил управление человеческими ресурсами как «стратегический и логически последовательный подход к управлению наиболее ценным активом предприятия: работающими там людьми, которые коллективно и индивидуально вносят вклад в решение задач предприятия» $[1$, с. 20]. М. Армсронг рассматривает управление человеческими ресурсами как фундаментальный критерий развития предприятия, стратегия управления интегрирована в стратегию развития всей организации. В рассматриваемом подходе подчеркивается важность приверженности работников миссии и ценностям организации. Человеческие ресурсы рассматриваются в качестве источника конкурентного преимущества, наряду с концепцией стратегии, основывающейся на ресурсах. Д. Гест и К. Легге, как и многие другие, считали, что стратегии работы с человеческими ресурсами необходимо интегрировать в стратегическое планирование бизнеса и использоваться для усиления организационной культуры. Управление трудом рассматривается как процесс и как система, одна из составляющих системы управления организацией. 


\section{ВЫВОДЫ}

В работе было выделено шесть основных этапов становления науки управления трудом, проанализированы предпосылки возникновения и особенности развития. Несмотря на то, что первым теоретиком менеджмента считается Ф. Тейлор, предпосылки для выделения такой отрасли науки как управление людьми и попытки теоретизировать практические наработки возникли еще ранее. Формирование научных школ управления трудом происходит с учетом специфичных особенностей конкретной экономики, региона и исторического контекста. Зачастую попытки перенять зарубежный опыт в управлении трудом заканчиваются неудачей в силу специфики конкретного предприятия, отрасли либо экономического или культурного региона. Однако это исключает возможности грамотно использовать теоретические разработки, как современные, так и прошедших лет, в целях повышения социальной и экономической эффективности управления трудом.

На современном этапе формируется концепция «управления человеческими ресурсами» как наиболее адекватная вызовам настоящего времени. Однако и она не может решить существующие проблемы в области управления трудовыми ресурсами. К глобальным проблемам в сфере трудовых отношений относятся недостаточно высокий уровень качественных характеристик рабочей силы в странах с формирующимися рынками, высокая стоимость рабочей силы в развитых странах, рост безработицы, распространение «незащищенных» форм занятости, нестабильная занятость, безработица среди молодежи, неравенство в области оплаты труда. Все эти проблемы могут привести не только к падению уровня жизни, но и к распространению социальных конфликтов.

\section{ЛИТЕРАТУРА}

1. Армстронг, М., Практика управления человеческими ресурсами. - 8-е изд. - СПб: «Питер», 2004. - 831 с.

2. Друкер, П. Ф. Классические работы по менеджменту / Питер Друкер, пер. с англ. - 2-е изд. - Москва: ООО «Юнайтед Пресс», 2010. -220 с.

3. Килин, И.С. Перспективы использования моделей А. Маслоу, К. Альдорфера, Ф. Херцберга для разграничения категорий «потребность» и «интерес». / И.С. Килин// Вессці Нацыянальная Акадэміі навук Беларусі. Серыя гуманітарных навук. - 2013. № 3. - С.61-64.

4. Костенко Е.П. Эволюция теории и практики управления персоналом в ХХ в. / Е.П. Костенко // Пространство экономики. - 2013. № 4. -С. 222-227.

5. Спивак, В.А. Организационное поведение и управление персоналом - СПб: Издательство «Питер», 2000. $-416 \mathrm{c}$

6. Тейлор Ф. Принципы научного менеджмента. - М, 1991. - 104 с.

7. Эпштейн, С. Буржуазная наука управления и неуправляемая экономика. - М. : Политиздат, 1986. - стр. 78 с.

8. Shaw Jonathan Harvard Magazine [В Интернете] // Who Built the Pyramids?. - 082003 г.. - 25052015 г.. http:/harvardmagazine.com/2003/07/who-built-the-pyramids-html. 